\title{
JURISTAS OU TÉCNICOS LEGALISTAS? REFLEXÕES SOBRE O ENSINO JURÍDICO NO BRASIL
}

\author{
Artenira da Silva e Silva ${ }^{1}$ \\ Maiane Cibele de Mesquita Serra ${ }^{2}$
}

\begin{abstract}
Resumo
O presente artigo possui como objetivo propor algumas reflexões críticas acerca da qualidade do ensino jurídico no Brasil. Para isso, analisou-se a evolução institucional histórica dos cursos de Direito no país, evidenciando os aspectos que culminaram para o panorama atual de ensino nas instituições consideradas, suas implicações e os seus reflexos na praxe jurídica nas Instituições do Sistema de Justiça. Além disso, aponta-se algumas propostas de solução para o enfrentamento do atual paradigma legalista de formação jurídica brasileira, uma vez que o modelo dogmático/positivista que ainda marca o momento vigente da formação em direito no país, não tem conseguido dar respostas positivas à maioria das antigas e novas demandas emergentes da sociedade contemporânea. Utilizou-se como metodologia a pesquisa bibliográfica e histórica.
\end{abstract}

Palavras-chave: Ensino jurídico. Crise. Modelo dogmático/positivista. Novo paradigma de ensino jurídico. Formação jurídica.

\section{INTRODUÇÃO}

A chamada "crise do ensino jurídico" vem sendo discutida sistematicamente no Brasil há pelos menos duas décadas. Segundo Streck (2011) e Machado (2005) a crise do ensino jurídico é, primordialmente, uma crise de paradigmas, marcada pelo esgotamento dos próprios paradigmas científicos da ciência do Direito e assentada em uma dupla face: uma crise de modelo e uma crise de caráter epistemológico.

Desde a sua implementação, os cursos jurídicos no Brasil apresentaram como principal característica a transmissão de um ensino jurídico meramente reprodutor de normas, suprimindo-se o entendimento de suas bases e primando por, na melhor das hipóteses, desenvolver exímios técnicos-legalistas, contribuindo oportunamente para o surgimento do termo "fábricas de bacharéis".

\footnotetext{
${ }^{1}$ Pós-doutora em Psicologia e Educação pela Universidade do Porto. Docente e pesquisadora do Departamento de Saúde Pública e do Mestrado em Direito e Instituições do Sistema de Justiça da Universidade Federal do Maranhão. Coordenadora de linha de pesquisa do Observatório Ibero Americano de Saúde e Cidadania e coordenadora do Observatorium de Segurança Pública (PPGDIR/UFMA/CECGP). Psicóloga Clínica e Forense. E-mail:

${ }^{2}$ Mestranda em Direito e Instituições do Sistema de Justiça, do Programa de Pós-Graduação em Direito da Universidade Federal do Maranhão (PPGDIR/UFMA). Bolsista CAPES. E-mail: maianeserra@hotmail.com
} 
O modelo dogmático/positivista marca ainda o atual momento do ensino jurídico do país e não tem conseguido acompanhar as transformações sociais, políticas, culturais e econômicas pelas quais o país têm passado, negligenciando a formação de profissionais críticos e transdisciplinarmente embasados para a atuação nas diferentes Instituições do Sistema de Justiça do país.

Além disso, esse ensino jurídico é caracterizado na atualidade pela mercantilização do ensino superior e sua despolitização, composto por conteúdos meramente tecnicistas e por uma cultura jurídica liberal, burguesa, individual, formalista e burocrática, iatrogenicamente reproduzida em nossa sociedade. (MACHADO, 2005).

Há um descompasso entre o país legal e o país real uma vez que o ensino do Direito excessivamente legalista e formalista não acompanha a realidade dinâmica e os anseios da sociedade contemporânea, o que o torna descontextualizado e consequentemente desacreditado frente aos jurisdicionados, consumidores finais da atuação profissional daqueles que atuam nas mais diversas áreas do direito, o que por sua vez, merece máxima atenção de todos que atuam na seara do ensino jurídico brasileiro, uma vez que ao desacreditar a atuação eficaz do Sistema de Justiça, a sociedade pode concorrer para a sedimentação de um regime de autotutela, a exemplo dos linchamentos noticiados país afora, em especial nos últimos 5 anos.

Sob esse aspecto, Martins (2015) afirma que o Brasil é um dos países que mais lincha no mundo, sendo um caso por dia, difundindo-se assim, uma tradição no que tange ao justiçamento popular. Nos últimos 60 anos, um milhão de brasileiros participaram de linchamentos. Segundo monitoramento realizado pela Sociedade Maranhense de Direitos Humanos (SMDH), no ano de 2016 foram registrados 27 linchamentos na região metropolitana de São Luís (com 29 mortes) e 11 casos no interior (com 13 mortes), totalizando 38 linchamentos com 42 mortes. $^{3}$

Nesse aspecto, a crise de representatividade das Instituições do Sistema de Justiça pode ser apontada como um dos principais fatores para que a população decida fazer justiça com as próprias mãos, tendo em vista que a lacuna deixada pelo Estado produz uma sensação de insegurança e impunidade, fazendo com que os cidadãos, respaldados em uma "pseudolegítima" defesa coletiva ante a um Estado ausente e ineficiente, se sintam responsáveis por restabelecer a ordem social ameaçada, disseminando violências endêmicas injustificáveis.

Para Machado (2005), o contexto educacional dos cursos superiores desdobrou-se em um ensino superior de caráter utilitarista, voltado para o aprendizado de um saber técnico/mecânico, distanciado das questões sociais como as supracitadas, contribuindo, consequentemente, para a despolitização e alienação da maioria dos estudantes e profissionais. Desta forma, essa realidade serve como lugar-comum para produção de um ensino jurídico que apenas atende às necessidades do capitalismo, da ideologia do Estado e das elites políticas e econômicas, desconectando-se da promoção da justiça e da paz social, exercendo a mesma função de formação

\footnotetext{
${ }^{3}$ Resumo do período (atualizado em 5 de janeiro de 2017).
} 
dos primeiros cursos jurídicos no Brasil do século XIX, qual seja, desenvolver a elite jurídica e política do Estado.

A metodologia utilizada neste artigo, consistiu, essencialmente, em pesquisa bibliográfica e histórica, a partir de materiais já existentes, bem como consultas de fontes normativas e documentos oficiais do Estado.

Este estudo possui como objetivo propor reflexões e críticas acerca da crise do ensino jurídico que assola o país, apresentando a análise da evolução histórica do ensino jurídico no Brasil, evidenciando os aspectos que culminaram para o quadro atual da crise, suas implicações e seus reflexos na praxe jurídica. Além disso, aponta-se algumas propostas de solução para o enfrentamento do atual paradigma no que tange ao ensino do direito no país.

\section{EVOLUÇÃO HISTÓRICA DO ENSINO JURÍDICO NO BRASIL}

Compreender a evolução histórica do Direito contribui para compreensão de como se estabeleceu o paradigma da crise do ensino jurídico no Brasil. Nesse sentido, conforme Martínez (2006) a evolução histórica do ensino jurídico no Brasil perpassa por três fases distintas, seguindo os modelos do estado liberal, social e neoliberal. A primeira fase iniciou-se com o desenvolvimento do paradigma liberal no Brasil Império. A segunda, com a República Nova, finalizando-se com os governos autoritários. A terceira iniciou-se com a Constituição Federal de 1988, a Portaria no 1.886/94 do MEC e a adoção de um modelo de estado neoliberal pelos governos a partir da década de 90 .

\section{Instituição dos cursos de direito no brasil e a gênese da crise do ensino jurídico}

A compreensão da evolução histórica acerca do ensino jurídico no Brasil remonta a tradição Ocidental europeia na qual os movimentos para a implantação de um ensino jurídico no Brasil iniciaram através da Faculdade de Coimbra. Por conseguinte, a metrópole objetivava impedir a criação de cursos superiores no Brasil temendo que a colônia pudesse se emancipar mais rapidamente, uma vez que um dos fortes vínculos do Brasil em relação a Portugal era a dependência administrativa da metrópole portuguesa.

Entretanto, os debates acerca da necessidade de implantação de um curso jurídico no Brasil, iniciaram-se após um contexto marcado pela recente proclamação da Independência (1822), efetivando-se após 327 anos de colonização portuguesa.

Os cursos jurídicos surgiram e começaram a funcionar com a criação do Estado Nacional Imperial brasileiro, sendo apresentado o primeiro projeto de criação e implantação de um curso jurídico no Brasil durante a Assembleia Constituinte de 1823, por Visconde de São Leopoldo, deputado pelo Estado do Rio Grande do Sul, formado em Direito em Coimbra, magistrado em Portugal, literato e político no Brasil. A partir de então, foram

\footnotetext{
${ }^{4}$ Fixa as diretrizes curriculares e o conteúdo mínimo do curso jurídico.
} 
iniciados os debates acerca dos objetivos do curso, centrado na finalidade social e institucional de formar bacharéis para compor a elite administrativa e política do país.

No Brasil do século XIX, não é difícil perceber qual será o papel do jurista ou bacharel. As escolas de direito, ou melhor, os cursos jurídicos, são explicitamente criados para prover o Império de quadros capazes de compor as carreiras burocráticas ou fazer aplicar as leis nacionais. Assim, o jurista nasce no Brasil diretamente ligado às funções do Estado, seja como funcionário, seja como profissional liberal, para fazer com que o Estado nacional atinja a capilaridade desejada, que o Estado português só havia conseguido em parte. (LOPES, 2008, p. 207).

Desta forma, o contexto da criação dos cursos jurídicos no Brasil foi marcado por disputas e lutas políticas relacionadas à consolidação da Independência do Brasil (BASTOS, 1978) e do projeto político nacional. (MOSSINI, 2010).

Emerso das contradições entre a elite imperial conservadora, vinculada ao aparato político colonizador, aos intuitos jurídicos metropolitanos, e a elite nacional civil, adepta dos movimentos liberais e constitucionais que sucederam à Revolução Americana e à Revolução Francesa, o incipiente Estado brasileiro, premido pela situação impositiva da igreja, que controlava sua infraestrutura de funcionamento cartorial e eleitoral, buscou nos cursos jurídicos a solução possível para a formação de quadros políticos e administrativos que viabilizassem a independência Nacional. (BASTOS, 2000, p. 01).

O surgimento do primeiro curso jurídico no Brasil visando atender as necessidades burocráticas da época se deu através da promulgação da Lei de 11 de agosto de $1827^{5}$, sancionada pelo imperador D. Pedro I, criando-se o Curso de Ciências Jurídicas e Sociais da Academia de São Paulo e o Curso de Ciências Jurídicas e Sociais em Olinda, mais tarde transferido para Recife.

Ao longo dos séculos, houve duas importantes reformas nos cursos jurídicos brasileiros: em 1854 através do Decreto no 1.386 , os cursos passaram a chamar-se Faculdades de Direito; e, além disso, transferiu-se o curso de Olinda para Recife; em 1879 houve a chamada reforma do "ensino livre", criando-se além das faculdades oficiais, as "faculdades livres", que deviam seguir as regras estabelecidas pelas oficiais. Salienta-se que o curso de Direito de 1827 possuía forte influência da Igreja, sendo incorporado inclusive ao currículo, a disciplina de Direito Eclesiástico, que tornou-se facultativa com a reforma de 1879 e, posteriormente, abolida definitivamente como disciplina do referido curso com a reforma de 1895 .

Rodrigues (1995) aponta as seguintes características acerca do ensino jurídico do Brasil durante o Império: 1. Controle centralizado pelo governo, do currículo, metodologia, nomeação dos professores e programas de ensino; 2. Predomínio do direito natural até 1870, com a introdução do positivismo; 3. Metodologia com aulas em estilo conferência, semelhante a Coimbra; 4. Local para a formação de filhos das elites econômicas no intuito de ocuparem postos importantes no país, e; 5. Descompasso com as mudanças sociais.

O início do século XX foi marcado pelo declínio da Escola de Recife e o Código Civil de 1916, de Clóvis Beviláqua, da Faculdade de Recife, demonstrando a importância que sua Escola possuía na época. (MOSSINI, 
2010).

Em 1911, a Reforma Rivadávia, baseada nas ideias do ensino livre viabilizou a autonomia corporativa das escolas, além disso, redefiniu a carreira do docente e criou também a necessidade de exames para o ingresso na Academia. No entanto, não versou sobre a formação do docente.

Em 1915, a Lei Carlos Maximiliano intentou organizar o ensino, criou a figura do professor catedrático, mas também não se manifestou acerca da formação específica dos docentes.

Já em 1927 findava a República Velha, conforme Siqueira (apudMartínez, 2006) com um saldo de 14 cursos de Direito e 3.200 alunos matriculados. O ensino jurídico nessa época, semelhante ao que aconteceu no período do Império, atrelava-se às bases ideológicas de defesa de um Estado liberal.

Assim, o ensino jurídico limitava-se ao processo de mera transmissão do conhecimento. Isso contribuiu para a reprodução da ideologia liberal na formação dos operadores do Direito, tendo em vista a estrutura metodológica deficiente e o direcionamento privatista das grades curriculares. À época, a norma jurídica era a única expressão de desenvolvimento na academia jurídica. (MORAES et al, 2014, p. 4-5).

Ademais, segundo Martínez (2006), a ausência de exigências qualitativas para a profissão de docente de Direito favoreceu a lei do mercado do "ensino livre", o que refletiu na expansão quantitativa do ensino jurídico no que tange a oferta de mão-de-obra docente. Além disso, a escolha dos lentes ${ }^{6}$ tinha por critério o sucesso profissional dos mesmos baseado em levar para as salas de aula os melhores práticos.

Essa fase encerra um momento de afirmação do Liberalismo na sociedade brasileira, cristalizado nos cursos de Direito por meio da baixa estruturação metodológica e do direcionamento privatista das grades curriculares. Isso contribuiu para a formação de um ciclo de reprodução da ideologia liberal na formação jurídica dos operadores brasileiros do Direito, contribuindo oportunamente para o surgimento do termo "fábricas de bacharéis". Desse modo, isolada pelo paradigma científico positivista, a academia jurídica teve seu único espaço de desenvolvimento a norma legislada, por sua vez cerceada de codificações. Esse isolamento do conhecimento jurídico, aliado à metodologia meramente de transmissão do conhecimento, revelou uma constância "industrial" também por ordem científica. Como na "fábrica" de montagem dos antigos "Ford T", essa seria a "standartização" da formação dos "bacharéis", cuja atuação prática como futuros lentes, aplicadores e legisladores do Direito, teria como substrato a reprodução contínua do modelo liberal em ênfase na sociedade. (MARTÍNEZ, 2006, p. 4-5).

Logo no início da Era Vargas (1930 - 1945), em 1930, foi criado o Ministério da Educação, e, posteriormente, em 1931, destaca-se a Reforma Francisco Campos que reestruturou o ensino superior com a elaboração do Estatuto das Universidades e cujo marco normativo foi o Decreto 19.851, de 11 de abril de 1931. O maior mérito da Reforma Francisco Campos foi "institucionalizar definitivamente a figura da "universidade" no Brasil, em nítida ação dirigida à inovação dos ideais educacionais da república velha." (MARTÍNEZ, 2006, p. 5).

Nesse período, as universidades vislumbravam uma nova orientação, voltada para a pesquisa, difusão da

\footnotetext{
${ }^{5}$ Versa sobre a criação dos Curso de Ciências Jurídicas e Sociais, um em São Paulo e outro em Olinda.

${ }^{6}$ Segundo o Dicionário Aurélio, "lente" é um sinônimo obsoleto do termo professor, mas, usualmente utilizado no período histórico em análise.
} 
cultura, com maior autonomia administrativa e pedagógica; acreditava-se no papel transformador da escola (Escola Nova). Entretanto, houve um choque inevitável entre os tradicionalistas e os adeptos da Escola Nova, prevalecendo a pedagogia tradicional para os cursos de Direito, sucumbindo as tentativas de inovação pedagógica.

A "Escola Nova" não conseguiu ser totalmente implantada porque seus ideais implicavam em uma profunda mudança qualitativa do nosso sistema de ensino, e encontraram como obstáculo a mentalidade reacionária e tradicionalista de vários educadores. (COTRIM; PARISI, 1979, p.270 apudMORAES et al, 2014, p. 6).

Importante salientar que nessa época, o curso de Direito criado em 1827 já vigorava há pelo menos 100 anos, porém, os conteúdos estudados ainda permaneciam praticamente inalterados. (SILVA, 2009). O ensino jurídico permaneceu praticamente estagnado de 1930 a 1945.

Nesse interim, Dantas (apud MARTÍNEZ, 2006) foi um dos pioneiros a se manifestar acerca do paradigma da crise no ensino jurídico, ao publicar em 1941, um texto acerca da “Renovação do Direito", atestando ser o curso formado por um "um museu de princípios e praxes, distante da ebulição legislativa e social da época". (apudMARTÍNEZ, 2006, p. 6).

No intuito de minimizar o caos já estabelecido, foi editada a Lei no 4.024/1961 - Lei de Diretrizes e Bases da Educação Nacional (LBD) 7 . Além disso, 1962 foi proposta uma alteração curricular, surgindo o chamado "currículo mínimo" para os cursos de Direito. Entretanto, sem o devido controle, o chamado "currículo mínimo" tornou-se, a rigor, um currículo máximo" (VENÂNCIO FILHO 1982, p. 318 apudMARTíNEZ, 2006, p. 7) e contribuiu ainda mais para que houvesse uma supervalorização do tecnicismo.

Na década de 1960, os cursos jurídicos se limitavam a um programa de formação técnicoprofissional, desconsiderando a formação humanística, social e política. $\mathrm{O}$ foco era atender à necessidade decorrente do crescimento econômico financiado externamente: a demanda por novos técnicos. (MORAES et al, 2014, p. 8).

Conforme Bastos (2000), pela conjugação de fatores: crise organizacional, didática, metodológica, curricular e mercadológica, esse foi um dos momentos de maior crise na história do ensino brasileiro.

Vislumbrando a crise que se instalava, a Ordem dos Advogados do Brasil, criada em 1930, elaborou a Lei Federal 4.215 de 27 de abril de $1963^{8}$ que estabeleceu o Estatuto da OAB, apresentando as exigências para o exercício da profissão. O exame de ordem, até então não era obrigatório para o exercício da profissão, o candidato poderia optar entre fazê-lo ou realizar um estágio no último ano da faculdade.

Novamente cogitou-se que a melhor solução para enfrentar a crise seria uma "nova reforma" na grade curricular. Assim, em 1972, os cursos de Direito sofreram uma modificação curricular por determinação da

\footnotetext{
${ }^{7}$ Fixa as Diretrizes e Bases da Educação Nacional. Instituiu que as universidades e estabelecimentos isolados de ensino superior, poderiam ser ministrados cursos de graduação, de pós-graduação, de especialização, de aperfeiçoamento, de extensão, dentre outros.

${ }^{8}$ Revogada pela Lei Federal 8.906/1994, atualmente em vigência.
} 
Resolução no 3, do Conselho Federal de Educação (CFE no 03/72) ${ }^{9}$. Entretanto, o resultado foi o mesmo da reforma de 1961, sem maiores inovações, e as faculdades de Direito continuaram seguindo os métodos tradicionais. (MARTÍNEZ, 2006).

Em virtude da limitação pedagógica das reformas educacionais, as duas décadas seguintes refletiram mais um período de estagnação no ensino jurídico brasileiro, o que gerou uma perda das oportunidades de transformação emancipatória, oriundas do período de "otimismo pedagógico" da Escola Nova e de Estado Social. (MARTÍNEZ, 2006). Desta forma, já no início da década de 90, havia no Brasil 186 cursos de Direito, os quais mantinham a mesma estrutura curricular tradicional desde a reforma de 1973, tendo como resultado a existência de um ensino legalista reprodutor, deformador e insatisfatório quanto à preparação dos bacharéis para a prática no mercado de trabalho. (MELLO FILHO, 1993).

Tais aspectos da crise "crônica" do ensino jurídico agora floresciam com toda a sua intensidade. Não havia mais o crescimento econômico do "milagre brasileiro" a absorver a vasta gama de profissionais "fabricados", com a formação minimamente técnica requerida. As exigências do momento demandavam profissionais do Direito, com qualificação superior àquela fornecida pelo ensino jurídico tradicional, aptos ao enfrentamento da complexidade dos conflitos, até então contidos pelo autoritarismo, cujo reconhecimento vinha no embalo da Constituição Federal de 1988. (MARTíNEZ, 2006, p. 8).

Em 1992, o Conselho Federal da OAB criou a Comissão de Ensino Jurídico iniciando um estudo nacional acerca do ensino do Direito no país. A conclusão do referido estudo resultou na Portaria 1.886/94 do MEC (já revogada), que revogou a Resolução CFE no 3/72 e passou a ditar as diretrizes curriculares mínimas para os cursos de Direito no Brasil. Tal portaria trouxe um avanço significativo no cenário educacional do Direito no país, com a adoção de importantes medidas, tais como: adoção de um currículo mínimo com disciplinas regulares, perfazendo 3.300 horas de carga horária, obrigatoriedade de apresentação de monografia ao final do curso, cumprimento de carga horária com atividades complementares, obrigatoriedade no estágio de prática jurídica, bem com a criação de um "Núcleo de Prática Jurídica" ${ }^{10}$. Em 1994, a aprovação no Exame de Ordem tornou-se obrigatória para o registro profissional.

Em 2001, a Comissão de Ensino Jurídico do Conselho Federal da OAB criou um programa de análise dos cursos de Direito no Brasil ${ }^{11}$.

Em 2004, dez anos após a expedição da portaria de 1994, surgiu um novo instrumento normativo visando regulamentar o ensino jurídico no Brasil. O Conselho Nacional de Educação editou a Resolução 9/2004 que novamente alterou as bases curriculares dos cursos de direito na tentativa de contextualizar o Direito com a

\footnotetext{
${ }^{9}$ Definiu o quadro geral das disciplinas do currículo mínimo, consolidando o ensino introdutório do conhecimento interdisciplinar e introduzindo a disciplina da "Prática Forense".

${ }^{10}$ Cf. Portaria 1.886/94 do MEC.

${ }^{11}$ Esse programa visa apontar os cursos jurídicos que têm obtido resultados favoráveis em avaliações oficiais, como no Exame Nacional de Cursos e no Exame da Ordem, concedendo um "selo" de recomendação para essas instituições.
} 
realidade social introduzindo alguns conteúdos de Antropologia, Ciências Políticas, Economia, Ética, Filosofia, História, Psicologia e Sociologia na grade dos cursos, traçando um novo perfil acadêmico para os cursos de Direito. O Artigo 3ํ da resolução 9/2004 expressa que:

Art. 3․ O curso de graduação em Direito deverá assegurar, no perfil do graduando, sólida formação geral, humanística e axiológica, capacidade de análise, domínio de conceitos e da terminologia jurídica, adequada argumentação, interpretação e valorização dos fenômenos jurídicos e sociais, aliada a uma postura reflexiva e de visão crítica que fomente a capacidade e a aptidão para a aprendizagem autônoma e dinâmica, indispensável ao exercício da Ciência do Direito, da prestação da justiça e do desenvolvimento da cidadania.

Embora tenham ocorridos diversas alterações e propostas de modificação no que tange ao ensino jurídico no Brasil, certo é que na sala de aula, não foi observado qualquer avanço. Muitas "inovações" acabaram representando somente mais um marco normativo para mudanças que deveriam ser cumpridas de modo contingente. Assim sendo, a reprodução de uma ideologia liberal associada a uma pedagogia tradicionalista permaneceu. Conforme Martínez:

Nesse ciclo de reprodução histórica de um padrão nos cursos de Direito, o seu "ponto de produção" ainda não pôde ser atingido de dentro para fora, ou seja, na evolução do ensino jurídico no Brasil ainda não ocorreu uma reforma voltada para a construção de inovações pedagógicas dentro das salas de aula, como se propunha com a Escola Nova. (2006, p. 10).

De posse da análise histórica supra detalhada, verifica-se que a crise que impera no ensino jurídico no Brasil originou-se a partir da sua própria criação e evolução histórica, regida pela necessidade predominante em atender demandas mercadológicas em detrimento de focar na prestação da justiça, do desenvolvimento da cidadania e da sedimentação da paz social.

\section{O CONTEXTO ATUAL DA CRISE DO ENSINO JURÍDICO NO BRASIL E SUAS IMPLICAÇÕES}

Conforme Gomes (2008) podemos sintetizar o paradigma da crise sob três focos: a. científicoideológico, b. político-institucional e c. metodológico.

O primeiro viés relaciona-se à perspectiva positivista legalista do Direito através da qual os direitos são observados exclusivamente através da letra da lei; quando o mais adequado seria o reconhecimento de que a lei é somente o ponto de partida de toda interpretação. Conforme pondera Dias:

[...] o juiz deve estar consciente de que as regras legais existentes não podem servir de limite à prestação jurisdicional. Ante situações novas, a busca de subsídios em regras ditadas para outras relações jurídicas tende a soluções conservadoras. Por outro lado, não reconhecer direitos sob o fundamento de inexistir previsão legal, assim como usar normas editadas para situações outras ou em diverso contexto temporal, nada mais é do que mera negação de direitos. [...] Se o fato sub judice se apresenta fora da normatização ordinária, uma resposta precisa ser encontrada, não só na analogia, nos costumes, e nos princípios gerais de direito, como ordena a lei civil, mas principalmente nos direitos e garantias fundamentais, que servem de base ao estado democrático de direito. (2004, 24-25). 
Desta forma, Gomes (2008) enfatiza que o ensino jurídico não pode permanecer ancorado na ideologia científica (estatalista e legalista) do século XVIII. O exegetismo dos cursos jurídicos revela o premente distanciamento científico que impera nos currículos jurídicos exageradamente normativos com a mera transmissão de um conteúdo genérico, dogmático, desconectado da realidade atual e muitas vezes inaplicável à solução de problemas. Tal pensamento tradicionalista no ensino do Direito vislumbra-se na aplicação de um modelo dogmático/positivista com um currículo fragmentado que abrange apenas uma concepção legalista, expressando o padrão jurídico normativo do Direito. Repousa aqui as bases de uma crescente judicialização de conflitos repetitivos, sobrecarregando todo o Sistema de Justiça, que ao não dar respostas satisfatórias aos conflitos levados a juízo, os faz retornar ao Sistema de Justiça, retroalimentando um ciclo vicioso crescente e interminável.

Isso porque "A forma como o currículo é elaborado, ou seja, fragmentado, acaba por tirar do aluno o interesse, uma vez que este mesmo currículo não se encontra em consonância com os interesses atuais do meio social em que vive". (LEISTER; TREVISAM, 2013, p. 53).

Sob essa perspectiva, Machado (2005) reconhece o Direito como uma instância ideológica dotada de dimensão valorativa, visto que está atrelado às relações de poder que privilegiam uma classe hegemônica, na qual interesses, desejos, ambições e valores permanecem ocultos diante de um suposto discurso de neutralidade ${ }^{12}$. Segundo o autor, o Direito funciona como um dos mecanismos repressivos de dominação da sociedade capitalista, tendo como elementos essenciais a normatividade e o poder exercido pelo Estado. E, justamente para manter a eficácia desse discurso ideológico, o princípio da legalidade que toma como base "a lei acima de tudo" constrói a ideia de um aparente consenso representando a "vontade geral" do povo.

Para Machado:

[...] todo discurso que se venha a fazer sobre o direito e sobre o seu método, por mais que se almeje fazê-lo de modo objetivo, com as conhecidas pretensões de verdade científica, sempre será um discurso ideológico, ou seja, um discurso que ao mesmo tempo em que visa descrever o fenômeno jurídico busca também produzir convencimento, ou até mesmo motivar as pessoas num ou noutro sentido em relação a esse fenômeno. (2005, p. 50).

Nesse sentido, o ensino jurídico seria uma verdadeiro "aparelho ideológico" que ao incorporar o método lógico-formal hipotético (o normativismo de Kelsen e de outros positivistas) "sempre acabaram por negar o valor reflexivo do discurso jurídico e o seu compromisso com a realização de valores no plano concreto e histórico”. (MACHADO, 2005, p. 55).

Do ponto de vista político-institucional tem-se um curso altamente mercantilizado com um aumento significativo dos cursos de Direito em todo o país. O termo "fábrica de bacharéis" que surgiu na 2a Revolução Industrial em uma alusão à produção em massa, pode ser coerentemente utilizado ainda hoje.

\footnotetext{
${ }^{12}$ A concepção de que as ciências constroem o discurso da neutralidade como forma de mascarar as relações de poder que a subsidiam, vai de encontro com as reflexões propostas pelo filósofo Michel Foucault.
} 
Segundo a $\mathrm{OAB}$, nos últimos 20 anos, houve uma explosão dos cursos jurídicos no Brasil: de aproximadamente 200 na década de 1990, para atualmente uma média de 1,3 mil existentes.

No início de 2013, o Ministério da Educação passou a represar a expansão dos cursos de Direito. E, em dezembro de 2013 determinou a suspensão do ingresso de alunos em 38 faculdades de Direito espalhadas pelo país. No entanto, tal repressão não teve efeitos práticos e houve aumento significativo de criação e ingresso de alunos nos cursos de direito em todo o país: 1.284 faculdades de Direito em 2014 e 1.308 faculdades de Direito em 2015. Destas, somente 139 possuem o selo de qualidade da OAB que avalia os índices de alunos aprovados nos exames da $\mathrm{OAB}$ e as notas do MEC. Além disso, são quase 800 mil advogados inscritos na entidade e cerca de três milhões não aprovados no Exame de Ordem, enquanto que o restante do mundo possui em torno de 1.100 cursos, ou seja, tem-se mais faculdades de Direito Brasil do que todos os demais países do globo terrestre juntos. (FREITAS, 2015), dado que claramente requer intensa reflexão crítica de todos os profissionais e estudantes de direito do país

A proliferação em massa dos cursos de direito brasileiros, sem correspondência qualitativa de atuação profissional dos alunos egressos é um processo incentivado pelas pressões sofridas nos rumos político e econômico, culminando na banalização do curso. Os cursos de Direito não exigem muitos gastos, não necessitam de laboratórios, nem de equipamentos sofisticados, carecem apenas de salas de aulas com um corpo de professores cuja remuneração é ínfima, com raras exceções. Associa-se a esse quadro problemático, a criação em 2004 do Programa Universidade para Todos (ProUni), aliado ainda ao Financiamento Estudantil (FIES).

Conforme Pellegrini "A lógica emergencial do Prouni, construído para suprir a baixa oferta de vagas em universidades públicas, tem reflexos diretos no modelo e na qualidade do ensino universitário brasileiro". (2014, p. $01)$.

Em entrevista à Carta Capital, o sociólogo, Wilson de Almeida, autor do livro "Prouni e o Ensino Superior Lucrativo em São Paulo", fruto da sua tese de doutorado, enfatiza que esse paradigma ajuda a consolidar um modelo de Ensino Superior que prioriza o lucro em detrimento da qualidade e questiona incentivos públicos à inclusão de estudantes de baixa renda em universidades privadas que ofertam um ensino "pasteurizado", considerando-se ainda que as escolas públicas de ensino fundamental e médio no Brasil efetivamente não preparam estes alunos com habilidades acadêmicas básicas (boa escrita, boa capacidade de leitura interpretativa e desenvolvimento de raciocínio lógico ) de modo a desenvolver o aprimoramento acadêmico ao longo da graduação.

O viés metodológico refere-se à falência no método clássico de ensino, sem liame entre teoria e prática com uma pedagogia tradicionalista onde o professor é mero expositor e o aluno um simples receptor. O currículo é voltado para operação da técnica em detrimento do exercício do saber, produzindo significativos efeitos na 
formação de verdadeiros "técnicos legalistas" e não juristas.

As Instituições de Ensino Superior (IES) passaram a se limitar à função certificatória, com propostas de trabalhos acadêmicos cada vez mais teóricos; preocupação exacerbada com acúmulo de conhecimento maçante, tradicional e obsoleto, verificado por meio de avaliações e trabalhos - seguindo o modelo de memorização e reprodução de informações; replicação de provas e trabalhos já utilizados pelo professor; despreocupação com a formação prática dos docentes, que comumente possuem baixa qualificação acadêmica, baixa produção científica e que vislumbram o ensino do Direito como um exercício funcional secundário em relação a outras práticas profissionais por eles exercidas. A responsabilidade por esse saber prático do aluno é quase que exclusivamente delegada aos estágios, que por sua vez, não são fiscalizados ou os são precariamente, onde "O objetivo é verificar se os alunos internalizaram os conteúdos lecionados pelo professor e se estão aptos a reproduzi-los". (ZUGMAN; BASTOS, 2013, p. 113).

[...] essa dinâmica traduz o entendimento de que não é importante avaliar o processo de formação do estudante, ou seja, o processo de produção do conhecimento. Em detrimento do processo de aprendizado, opta-se por um único momento avaliativo, cujo objetivo é a avaliação de um produto, o qual muitas vezes não exige mais do que a mera memorização de conceitos. (GHIRARDI, 2012 apudZUGMAN; BASTOS, 2013, p. 113).

Além disso, a função certificatória dos cursos jurídicos é associada à dinâmica de funcionamento do mercado jurídico hodierno.

[...] às instituições de ensino cabe apenas certificar os alunos capazes de replicar as informações transmitidas pelos professores. Esse certificado permite a participação em concursos públicos e na advocacia, mediante aprovação no exame da $\mathrm{OAB}$, ambos seguindo o modelo de memorização e reprodução de informação e não de construção do conhecimento. Ou seja, a realidade além dos muros da universidade também é pautada pela prevalência do produto sobre o processo. (ZUGMAN; BASTOS, 2013, p. 113-114).

Alia-se tudo isso, a precária formação pedagógica dos docentes que acabam por transformar o ensino jurídico em uma simples leitura de códigos, leis e tratados, com matérias fragmentadas e desconexas da realidade, apresentando conceitos universais que independem do mundo fático. Além da ausência quase total da pesquisa como elemento de ensino.

Ademais, a maior parte dos professores não atua em regime de dedicação exclusiva, exercendo outra atividade concomitante ao magistério ${ }^{13}$. Isso se reflete na função certificatória de muitas instituições que utilizam esses docentes como cases de sucesso no intuito de atrair uma clientela que almeja êxito em promissoras carreiras jurídicas. (ZUGMAN; BASTOS, 2013).

Diante de todos os apontamentos que refletem o paradigma atual da crise do ensino jurídico, percebe-se que a maior problemática do quadro se reproduz no impacto desta na praxe jurídica, afetando negativamente a

\footnotetext{
${ }^{13}$ Conforme pesquisa do Núcleo de Metodologia de Ensino, da Escola de Direito de São Paulo da Fundação Getúlio Vargas, formulada a partir de banco de dados levantado pelo Instituto Nacional de Estudos e Pesquisas Educacionais Anísio Teixeira (INEP), apenas 33\% dos professores das faculdades de Direito do Brasil atuam em regime de dedicação exclusiva.
} 
sociedade como um todo.

\section{Os reflexos da crise da formação em direito na praxe jurídica brasileira}

O modelo de ensino jurídico que vigora ainda nos dias atuais, não é reflexivo-transformador, mas pautado por um ensino dogmático, objetivando, na melhor das hipóteses, a transformação do aluno em um técnico-legalista mediano e, consequentemente, visando apenas a conclusão do curso. O excesso de aulas expositivas, atreladas à falta de didatismo e sobra de hermetismo na postura de muitos profissionais, com a supervalorização da prolixidade como suposta qualidade do profissional do direito contribuem para a formação de um pensamento totalmente despolitizado e disciplinador, culminando ainda na ausência de intersubjetividade na relação professor-aluno.

A escola, como os quartéis e as fábricas, segundo Michel Foucault, funciona como instrumento da mecânica do poder disciplinador. A disciplina, produzida por meio dessas instituições, segrega as mentes. Essa disciplina da era da técnica é a disciplina que se observa em salas de aula, na relação provocada entre professor e alunos, em que não há intersubjetividade, não há troca, apenas um ritual destinado a conferir àquele que aprende a técnica que ele mesmo julga necessária e suficiente para haver-se com o mundo, porque o que ele precisa é que lhes sejam dadas as respostas existentes para o enfrentamento da representação que ele tem do mundo. Trata-se de uma transformação inumana, artificial, tendente a realizar as necessidades também artificiais de um mundo presentificado como espaço de fabricação e de consumo, não de relações humanas. Desaparece o propriamente humano para que a técnica apareça. A situação se inverteu, o homem não busca sua formação, como indivíduo, como comunidade, ele procura um dispositivo que altere sua essência, não no sentido que ele é. $O$ diploma não é mais o resultado de uma caminhada, formadora, transformadora. (PÊPE; HIDALGO, 2013, p. 287 - 288).

A preponderância dada às disciplinas dogmáticas em detrimento das zetéticas ${ }^{14}$, valorizando, sobremaneira, a carga normativa na seara jurídica, reflete-se em um ensino enciclopédico que gera consequências drásticas, reveladas na atividade desempenhada pelos agentes do sistema de justiça, totalmente limitados no que tange aos conhecimentos transdisciplinares; dispondo, na melhor das hipóteses, na aplicação maciça da letra da lei e, muitas vezes, com completa hipossuficiência técnica quanto a assuntos específicos, problemática vislumbrada nas decisões judiciais.

Atualmente, é visível que a política de massificação do ensino jurídico consumou essa tendência de privilegiar matérias e disciplinas tecnológicas nas grades curriculares das faculdades de direito, em detrimento daquelas que apresentam um conteúdo mais humanístico e reflexivo. Tais opções curriculares podem ser entendidas até mesmo como

\footnotetext{
${ }^{14}$ Segundo Tercio Sampaio Ferraz Júnior, as disciplinas zetéticas são, por exemplo, as investigações que têm como objeto o direito no âmbito da Sociologia, da Antropologia, da Psicologia, da História, da Filosofia, da Ciência Política etc. Essas disciplinas servem não só para informar os juristas, mas, principalmente, para formá-los. Por sua vez, as "dogmáticas são definidas à medida que consideram certas premissas, em si e por si arbitrárias, como vinculantes para o estudo, renunciando-se, assim, ao postulado da pesquisa independente. Ao contrário das disciplinas zetéticas, cujas questões são infinitas, as dogmáticas tratam de questões finitas". (FERRAZ JÚNIOR, 2012, p. 24). Exemplos de disciplinas dogmáticas seriam as voltadas estritamente ao Direito Constitucional, Penal, Civil, Administrativo, e os demais.
} 
parte da estratégia de despolitização do jurista e atrofia do seu senso crítico, como ingredientes necessários para garantir a inteira subserviência dos profissionais do direito aos reclamos de mercado. (MACHADO, 2005, p. 112).

Ademais, a forma como o currículo é apresentado, de modo fragmentado e desconexo mostra-se insuficiente para atender às novas demandas sociais, afastando o aluno da realidade social. Segundo Gabriel Chalita:

O século XXI apresenta uma enorme gama de desafios para o estudioso e o cientista do Direito. A sociedade em transformação exige uma resposta constante na solução de seus conflitos. A pessoa humana não é estática, não se satisfaz, e isso gera um conflito continuado de expectativas individuais e coletivas. Novas tecnologias, novas fontes de informação, novos domínios da ciência, e o Direito não pode ficar à margem pois que trata do mister de fazer justiça, de restabelecer o sentido e a opção de vida em grupo que gerou a própria sociedade. Evidentemente, a sociedade contemporânea não tem um sentido de opção, o Estado se configura uma necessidade. Não há alternativa de se fazer parte ou não do Estado, a questão é de solução dos conflitos que se repetem e dos novos desafios gerados por novas posturas da sociedade. (2005, p. 229-245).

O currículo do ensino jurídico, representando uma concepção legalista do Direito onde as leis são interpretadas, de uma única forma (racional e positivista), quando não o são interpretadas ou deturpadas de modo completamente ao acaso ou, por vezes, em direção oposta à letra da lei, limita o profissional, interferindo negativamente no desenvolvimento da sua atividade laboral.

Enquanto as instituições de ensino jurídico estiverem comprometidas somente com a especialização das matérias dogmatizadas e com uma formação necessária para que o aluno de Direito tenha a possibilidade de passar em um futuro exame da Ordem dos Advogados do Brasil, não se preocupando com a carreira realística de um jurista realmente preocupado com o social, com a justiça e com a sociedade em si, continuarão surgindo no mercado profissionais do direito preocupados somente com sua carreira financeira e despreocupados com a função da justiça legada constitucionalmente a eles. (LEISTER; TREVISAM, 2013, p. 64-65).

Desta forma, esse paradigma da crise jurídica reflete-se de maneira mais contundente na praxe do ator jurídico, uma vez que ao operar o Direito, o conjunto de práticas e valores desenvolvidos na formação profissional serão agora aplicados socialmente, refletindo no seu papel civil.

Assim, o paradigma jurídico reproduzido nas universidades, por exemplo, não permite ao juiz criar o Direito ou interpretá-lo de modo a atender novas demandas sociais, cabendo-lhe exclusivamente aplicar as normas de forma dedutivista lógico-formalmente, mediante um simples processo de subsunção que é caracterizado como a adequação do fato à norma, como sendo um conceito pronto e acabado. (FILHO, 2013).

O jurista formado por escolas, convém lembrar, não será apenas advogado: será também o juiz que fará parte, afinal de contas, de um dos poderes políticos do Estado. A alienação do jurista, deste modo, colabora também na supressão das garantias de direitos. É que o centro de equilíbrio social (ou de legitimação) é colocado na eficiência, não no bem do homem. Começa-se a falar em um bem comum que só existe nas estatísticas dos planejadores, mas que a pobreza dos centros urbanos desmente. E, em nome desse bem comum, alcançável pela eficiência, sacrificam-se alguns valores que talvez não fosse inútil preservar. (FARIA, 1987 apudSTRECK, 2014).

Percebe-se que há ciclo vicioso que desemboca de modo nefasto na sociedade de modo geral: a postura 
dogmática e tradicional dos docentes é reflexo do paradigma proposto que, por sua vez, é repassado aos discentes que operacionalizam os mesmos valores de um "discurso racional falsamente neutro, dogmático e tecnicista, cuja existência somente se justifica para a manutenção de privilégios e desigualdades sociais seculares." (MARTÍNEZ, 2005, p. 01).

Além desses reflexos na praxe jurídica, segundo Machado (2005), o ensino jurídico no Brasil funciona como "indústria cultural" de fabricação do senso comum do Direito com o aumento da privatização e, consequentemente, o aumento da mercantilização; massificação das obras de Direito (caracterizadas por resumos de dogmática jurídica); eventos culturais supostamente científicos, mas de cunho empresarial; além da proliferação dos cursinhos jurídicos - autênticos negócios empresariais (oferecendo desde preparatórios para concursos até cursos de especialização). Tais fatores contribuem para reforçar o modelo normativo e a cultura tecnicista e despolitizada que marca o ensino jurídico no Brasil.

Para Machado, essa indústria cultural apresenta uma dupla faceta:

Essa indústria cultural do direito, se, por um lado, exibe a impressão de que se verificou um saudável aumento da produção científica na área do conhecimento jurídico, pela oferta de todo tipo de obra e pela suposta democratização da cultura, com o aumento das possibilidades de acesso a livros, cursos e eventos culturais; por outro, representa também uma espécie de massificação da cultura jurídica, com a consequente queda da qualidade da produção científica nessa área e com o impressionante aumento dos produtos repetitivos e superficiais, que atendem muito mais às exigências do mercado do que, propriamente, às necessidades culturais dos bacharéis e profissionais do direito. (2005, p. 19).

Este "senso comum jurídico" reforça a reprodução mecânica da legalidade em detrimento da reflexão, gerando uma desnecessidade da análise acadêmica crítica dos produtos do trabalho dos operadores do direito brasileiro (peças processuais, pareceres ministeriais, decisões e sentenças judiciais) e tem como principal impacto a ilusória neutralização do comportamento profissional do Direito, subserviente a um pensamento acrítico ante às novas tendências que produzem o saber jurídico e também a-histórico ao tomar a norma como algo ideal. (MACHADO, 2005).

\section{EM BUSCA DE UM NOVO PARADIGMA: UM ENSINO JURÍDICO VOLTADO PARA MUDANÇA SOCIAL}

Como já vislumbrado, o ensino do direito no país passa por um momento crítico, havendo uma limitação do direito positivo que não se mostrou suficientemente eficaz para responder às demandas da sociedade contemporânea onde o direito kelsiano não mais consegue suprir e subsistir diante do aumento da complexidade das relações sociais modernas. "A ideia de um sistema fechado, imune a contradições, sem lacunas e absolutamente lógico-formal não dá conta de responder a relações multifacetárias e diferenciadas". (FILHO, 2013, p. 80). 
Nesse sentido, faz-se necessário propor novos rumos para produção de um ensino jurídico comprometido com a mudança social. Assim, o Direito deve servir como ferramenta transformadora das relações sociais, e tais mudanças, conforme Machado (2005) passam pelo crivo da transformação da postura do advogado em um profissional atuante na defesa do interesse público; mudança na condição do Ministério Público como um quarto poder capaz de atuar em proveito da sociedade e ainda a configuração da Magistratura como um poder independente, imune aos interesses de poder multivariados que muitas vezes sobrepõem-se às decisões judiciais.

Além disso, o autor propõe que essas mudanças não podem dissociarem-se das inerentes ao campo do ensino jurídico, o que implica em transformações nas "empresas" de produção/fabricação de advogados em meros técnicos-legalistas, rompendo a formação tecnicista e despolitizada que é fruto da hegemonia dogmática.

Trata-se, na verdade, da adoção de um novo paradigma do ensino jurídico chamado de "ramo centrífugo" conforme Lyra Filho (apud MACHADO, 2005) em que há o alargamento do foco jurídico em virtude da pluralidade jurídica na qual o Estado não é a fonte exclusiva do Direito e nem mesmo o formalismo positivista, o único modelo de ensino jurídico válido.

Desta forma, Machado (2005) seguindo justamente a Resolução 9/2004 (mais precisamente o art. 2º, $\$ 1^{\circ} \mathrm{e}$ art. $4^{\circ}$ ) que alterou as bases curriculares dos cursos de graduação com escopo de contextualizar o Direito com a realidade social, propõe uma nova proposta pedagógica para os cursos de Direito: formação voltada para o caráter humanístico; formação interdisciplinar; operação criativa do Direito; formação axiológica voltada para o desenvolvimento do senso ético do profissional; competência para solucionar problemas e conflitos do mundo contemporâneo; capacidade para conciliar o exercício da vida profissional com o exercício da cidadania em detrimento de formar um profissional muitas vezes apto para o oposto, ou seja, fomentar e acirrar conflitos, o que é frequentemente perceptível em conteúdos agressivos de peças produzidas e ajuizadas.

Há a necessidade premente de pensar em uma avaliação estruturada na reflexão do Direito, e não na sua repetição ou memorização. Através de questões que integrem conhecimentos de diversas áreas do saber (não apenas jurídicas), gera-se a possibilidade de compreender que os problemas do mundo são complexos, sendo, portanto, indispensável uma transformação transdisciplinar e transversal no ensino.

A emergência dos chamados "novos direitos", preocupados sobretudo com as relações interdisciplinares e com as dimensões sociais, políticas, econômicas e culturais da sociedade faz-se necessária, destacando-se, a ênfase na formação em conteúdos transdisciplinares daqueles que vão operar os Sistemas de Justiça. Portanto, não se trata simplesmente de criar disciplinas ou produzir um currículo bem elaborado, o importante é que a interdisciplinaridade e a transversalidade se alimentem mutuamente, desembocando na transdisciplinaridade dos cursos de direito brasileiros. 
Essa interligação entre as disciplinas e a realidade se dá pela relação entre o método de ensino e a experiência da pesquisa do conhecimento que gerará a sabedoria. Isso define o método como possibilidade de encontrar nos detalhes da vivência concreta e individual a totalidade de seu significado. [...] Para tanto, necessário se faz que no ensino seja usado um método que se relacione com a teoria de modo eficaz, despertando a curiosidade do aluno em uma perspectiva complexa. Isso se dará a partir do uso dos problemas da sociedade inseridos no contexto da teoria, juntamente com estudos de casos que tragam os alunos para uma percepção dessa relação, preparando-se para o enfrentamento da realidade fora dos portões da instituição de ensino. (LEISTER; TREVISAM, 2013, p. 55).

Ademais, há a necessidade de uma nova formação pedagógica vinculada a uma mudança de concepção para o novo paradigma do ensino jurídico aos docentes dos cursos de Direito, tendo a postura do professor não como o centro da aula, mas como um provocador do debate em classe, problematizando a todo instante o material de leitura e as afirmações feitas pelos alunos, atuando como um verdadeiro mediador.

[...] os professores devem ser capazes de construir um tipo especial de profissionalismo, no qual: a) promovam um aprendizado cognitivo profundo; b) sejam comprometidos com uma aprendizagem profissional contínua; c) aprendam a ensinar de modo diferente de como foram ensinados por seus antigos mestres; d) trabalhem e aprendam com seus pares (em grupos); e) desenvolvam a capacidade de mudar, arriscar e pesquisar; f) construam, nas instituições educativas, organizações de aprendizagem. (PACHANE, 2012, p. 310).

Nesse sentido, o saber deve ser construído em uma relação entre os atores: professor e aluno, na qual ambos aprendam a pensar o novo, compreendendo-se e compreendendo os outros, através de uma metodologia participativa, desenvolvendo assim, o relacionamento interpessoal, em avaliação crítica de casos concretos, peças processuais, pareceres ministeriais, decisões e sentenças judiciais, relacionando permanentemente teoria e prática jurídicas. Para isso, faz-se necessário a aplicação de um projeto pedagógico que valorize a pesquisa e a dedicação acadêmica.

Para que tais modificações possam surtir efeito, Machado (2005) elenca algumas alterações necessárias na prática da formação em direito: inserção de novas disciplinas que levem em conta as novas demandas sociais do mundo globalizado, flexibilizando a grade curricular; diminuição da carga horária das disciplinas pertinentes ao direito privado e aumento das disciplinas do eixo dos "novos direitos".

Além disso, outras propostas são igualmente necessárias, tais como, a simulação de audiências e outras rotinas profissionais dos mais variados ramos do Direito, havendo uma rotatividade dos papéis exercidos pelos alunos; visitas monitoradas a fóruns, cartórios e tribunais, além de empresas e escritórios a fim do discente conhecer o dia a dia dessas instituições, aplicando teoria e prática. (ALMEIDA; SOUZA, 2013) ${ }^{15}$. Edgar Morin elucida que:

Todas as reformas da Universidade concebidas até agora têm girado ao redor de um buraco negro que concerne à necessidade profunda do ensino. Estas reformas têm sido incapazes de percebê-la, porque se encontram atreladas a um tipo de inteligência que é preciso reformar. Existe, assim, uma ligação de circularidade entre esses imperativos interdependentes: 1.

\footnotetext{
${ }^{15}$ Algumas dessas soluções já são propostas nas Diretrizes Curriculares Nacionais (Resolução 9/2004), entretanto, não há efetiva aplicabilidade
} 
Reproblematização dos princípios do conhecimento e problematização daquilo que aparentava ser a solução; 2. Reforma do pensamento por um pensamento complexo capaz de ligar, contextualizar e globalizar; 3. Transdisciplinaridade. (2009, p. 22).

Resta claro que o momento vivenciado clama por mudanças profundas. Somente quando alunos, juntamente com docentes, instituições de ensino e o próprio governo estiverem imbuídos num mesmo ideal que implica em uma mudança na mentalidade jurídica, com a substituição de paradigma do ensino jurídico tradicional para um novo paradigma voltado para a justiça, democracia e comprometimento com a sociedade civil, pode-se pensar na formação de verdadeiros juristas com conhecimentos amplos e interligados a outras áreas do saber, e não mais na formação de meros técnicos-legalistas medianos, cujas atuações práticas apenas acentuam a crise de sobrecarga do Sistema de Justiça, pela judicialização de demandas repetitivas que não encontram solução na prática atual do exercício do direito.

\section{CONSIDERAÇÕES FINAIS}

A crise do ensino jurídico enfrentada na atualidade é o cume de todo o seu desenvolvimento histórico, uma vez que as reformas e mudanças observadas durante toda a evolução do ensino do Direito quase sempre ocorreram a fim de satisfazer necessidades mercadológicas.

Além disso, uma das grandes dificuldades encontradas em termos de educação (jurídica) na atualidade está associada à mantença de um paradigma inadequado diante de uma sociedade complexa. A chamada "crise dos paradigmas" conforme proposto por Streck (2011) e Machado (2005) não proporciona mais novas diretrizes e rumos para os problemas científicos da contemporaneidade, desdobrando-se em um conjunto de equívocos.

A crise epistemológica assentada no normativismo como objeto, no raciocínio lógico-formal como metodologia, no liberalismo como sustentáculo ideológico e na mentalidade positivista como base do saber jurídico dotado de uma cultura tecnicista e despolitizada marca o ensino jurídico no Brasil, mostrando-se insuficientemente para responder às demandas da sociedade contemporânea, dirimindo conflitos em direção da sedimentação da paz social.

O paradigma da crise é composto por uma teia de fatores: a ideologia formada no âmbito do Direito em nome de uma "neutralidade científica" ilusória, para não dizer delirante, desemboca em um ensino normativista/dogmático com docentes muitas vezes sem formação pedagógica, sem qualificação acadêmica, sem produção científica e sem conhecimentos transdisciplinares básicos. A ampliação do número de instituições de ensino de direito gera o fenômeno da mercantilização, aumentando o prestígio da dogmática jurídica, pois grande parte dos cursos oferece um ensino focado na leitura dos mesmos manuais, gerando consequentemente, o aumento de alunos que formam-se sendo profissionais acríticos e despolitizados, técnicos-legalistas medianos.

Além disso, a falha do sistema educativo (jurídico), consiste ainda na manutenção de um sistema 
avaliativo focado em única maneira de pensar o ensino, onde a busca pela certeza e segurança (próprias do paradigma mecanicista moderno) impossibilita a abertura de espaço para o novo. Ademais, o Exame de Ordem, os concursos públicos e os demais meios avaliativos daqueles que irão integrar as mais diversas áreas de atuação jurídica encontram-se sustentados por esse mesmo padrão de conhecimento, dificultando uma reflexão e observação diferenciada do sistema educativo jurídico.

Dentro dessa perspectiva pedagógica, os processos avaliativos (sendo a $\mathrm{OAB}$ um deles), funcionam como controladores epistemológicos do ensino, contribuindo para uma estrutura educativa resistente às mudanças que uma sociedade complexa exige. Apesar de se manifestar criticamente em relação à qualidade dos cursos jurídicos, a $\mathrm{OAB}$, assim como diversos outros meios que avaliam o ensino, exercem suas críticas de modo contraditório, propondo estruturas avaliativas incapazes de cumprir com os objetivos de assegurar a formação de um profissional apto a apresentar respostas aos problemas da sociedade.

$\mathrm{O}$ momento experienciado traz consequências drásticas sobretudo para sociedade que carece de um sistema jurídico formado por valores equânimes. Conforme Junqueira e Fonseca (2000) o ensino jurídico traz efeitos nocivos ao estudante de direito, uma vez que o idealismo do primeiro ano é logo substituído pelos valores do mercado de trabalho, onde as mudanças sociais e a concretização da justiça são completamente ignorados por compromissos e funções meramente mercadológicas.

Desta forma, o ensino jurídico clama por um novo paradigma voltado para a mudança social com um currículo emancipatório de caráter transdisciplinar capaz de gerar nos discentes o exercício da cidadania e a competência necessária para que possam verdadeiramente exercer suas funções de operadores do direito efetivamente preocupados com a sociedade de uma forma ética e humanitária, de fato contribuindo para a resolução e não para a proliferação de conflitos a serem crescentemente judicializados, sobrecarregando todas as instituições que compõe o Sistema de Justiça no Brasil.

\section{JURISTS OR TECHNICAL LEGALISTS? REFLECTIONS ABOUT LAW EDUCATION}

\section{IN BRAZIL}

\section{Abstract}

This paper aims to propose some critical reflections about the quality of legal education in Brazil. For that, the historical institutional evolution of the Law courses in the country was analyzed, highlighting the aspects that culminated for the current overview of law education in the considered institutions, their implications and their reflexes in the legal praxis of the Brazilian Justice System Institutions. In addition, some proposals for a solution to the current legalistic paradigm of Brazilian legal formation are pointed out, since the dogmatic/positivist model that still marks the current moment of law formation in the country has failed to provide positive answers to the majority of the old and new emerging demands of contemporary society. Bibliographic and historical research 
were used as methodology.

Keywords: Legal education. Crisis. Dogmatic/positivist model. New paradigms in law education. Legal training.

\section{REFERENCIAS}

ALMEIDA, Frederico de Almeida; SOUZA, André Lucas Delgado; CAMARGO, Sarah Bria. Direito e realidade: desafios para o ensino jurídico. In.: Ghirardi, José Garcez e Feferbaum, Marina. Ensino do direito em debate: reflexões a partir do $1^{\circ}$ Seminário Ensino Jurídico e Formação Docente /São Paulo: Direito GV, 2013.

BASTOS, Aurélio Wander. O ensino jurídico no Brasil. 2 ed. Rio de Janeiro: Lumen Júris, 2000, p. 1.

Os cursos jurídicos e as elites políticas brasileiras: ensaios sobre a criação dos cursos jurídicos. Brasília: Câmara dos Deputados. Centro de Documentação e Informação, 1978.

BRASIL. Conselho Nacional de Educação. Câmara de Educação Superior. Resolução n9, de 29 de setembro de 2004. Disponível em: <http://portal.mec.gov.br/cne/arquivos/pdf/ces0920 04direito.pdf >. Acesso em: 03 jan. 2017.

CHALITA, Gabriel B. I. Heurística e Direito. In.: BOUCAULT, Carlos E. de Abreu; RODRIGUES, José Rodrigo. (Org.). Hermenêutica plural. São Paulo: Martins Fontes. 2005.

DIAS, Maria Berenice. Conversando sobre justiça e os crimes contra mulheres. Porto Alegre: Livraria do Advogado Editora, 2004.

FERRAZ JR., Tercio Sampaio. Introdução ao estudo do direito: técnica, decisão, dominação. São Paulo: Atlas, 2012.

FILHO, Roberto Freitas. As normas abertas e o método do ensino jurídico. In.: Ghirardi, José Garcez e Feferbaum, Marina. Ensino do direito em debate: reflexões a partir do $1^{\circ}$ Seminário Ensino Jurídico e Formação Docente /São Paulo: Direito GV, 2013.

FREITAS, Vladimir Passos de. Excesso de faculdades de Direito implode o mercado de trabalho. Revista Consultor Jurídico, 6 de setembro de 2015. Disponível em: < http://www.conjur.com.br/2015-set-06/segundaleitura-excesso-faculdades-direito-implodem-mercado-trabalho>. Acesso em: 02 jan. 2017.

GOMES, Luiz Flávio. A crise (tríplice) do ensino jurídico. Disponível em: < http://www.egov.ufsc.br/portal/sites/default/files/anexos/29134-29152-1-PB.pdf $>$. Acesso em: 09 jan. 2017.

JUNQUEIRA, Eliane Botelho; FONSECA, Maria Guadalupe Piragibe da. O profissional do Direito no Terceiro Milênio. In.: RODRIGUES, Horácio Wanderlei (Org.). O Direito no Terceiro Milênio. Canoas: ULBRA, 2000.

LOPES, José Reinaldo de Lima. O direito na história: lições introdutórias. 3. ed. São Paulo: Atlas, 2008.p. 207.

LEISTER, Margareth Anne; TREVISAM, Elisaide. A necessidade da transversalidade no ensino jurídico para uma efetiva contribuição do jurista no desenvolvimento da sociedade: um olhar segundo reflexões de Edgar Morin. In.: 
Ghirardi, José Garcez e Feferbaum, Marina. Ensino do direito em debate: reflexões a partir do $1^{\circ}$ Seminário Ensino Jurídico e Formação Docente /São Paulo : Direito GV, 2013.

MACHADO, Antonio Alberto. Ensino jurídico e mudança social. Franca: Edunesp, 2005.

MARTÍNEZ, Sérgio Rodrigo. Reflexões sobre o ensino jurídico. Revista Jus Navigandi, Teresina, ano 10, n. 654, 22 abr. 2005. Disponível em: <https://jus.com.br/artigos/6613>. Acesso em: 13 jan. 2017.

A evolução do ensino jurídico no Brasil Jus Navigandi, Teresina, ano 10, n. 969, 26 fev. 2006. Disponível em: <http://www.egov.ufsc.br/portal/sites/default/files/anexos/29074-29092-1-PB.pdf>. Acesso em: 13 jan. 2017.

MARTINS, José de Souza. Linchamentos: a justiça popular no Brasil. São Paulo: Contexto, 2015

MELO FILHO, Álvaro. Por uma revolução no ensino jurídico. Revista Forense. Rio de Janeiro, v.322, ano 89, abr./jun. p.09-15, 1993.

MORAES, Patrícia Regina de et al. O ensino jurídico no Brasil. São Paulo: União das Instituições de Serviços, Ensino e Pesquisa LTDA (UNISEPE), 2014.

Disponível em: <http://www.unifia.edu.br/revista_eletronica/revistas/direito_foco/

artigos/ano2014/ensino_juridico.pdf>. Acesso em: 05 jan. 2017.

MORIN, Edgar. Educação e complexidade: os sete saberes e outros ensaios. In.: ALMEIDA, Maria da C.; CARVALHO, Edgard de A. (Orgs.). São Paulo: Cortez, 2009.

MOSSINI, Daniela E. de S. Ensino Jurídico: história, currículo e interdisciplinaridade. Doutoramento em Educação: Currículo PUC-SP, São Paulo, 2010 - 256 f. Tese (doutoramento) - Pontifícia Universidade Católica de São Paulo.

PACHANE, Graziela Giusti. Quem é seu melhor professor universitário e por quê? Características do bom professor universitário sob o olhar de licenciandos. Educação (UFSM), v. 37, p. 307-320, 2012. Disponível em: $<$ https://periodicos.ufsm.br/ reveducacao/

article/view/2926/3242>. Acesso em: 02 jan. 2017.

PELLEGRINI, Marcelo. Prouni criou milionários em troca de má qualidade na educação. Carta Capital, 19 de dezembro de 2014. Disponível em: <http://www.cartacapital.com.br/educacao/prouni-criou-milionarios-emtroca-de-ma-qualidade-na-educacao-7396.html>. Acesso em: 03 jan. 2017.

PÊPE, Albano Marcos Bastos; HIDALGO, Daniela Boito Maurmann. Da Disciplina à Transdisciplinaridade pela Transgressão Waratiana: uma releitura heideggeriana do ensino jurídico. Seqüência. UFSC, Florianópolis, SC, Brasil, ISSNe 2177-7055.Disponível em: <http://www.scielo.br/pdf/seq/n66/12.pdf>. Acesso em: 03 jan. 2017.

RODRIGUES, Horácio Wanderlei. Novo currículo mínimo dos cursos jurídicos. São Paulo: RT,1995

SILVA, Daniel Pereira Militão. Desafios do ensino jurídico na pós-modernidade: da sociedade agrícola e industrial para a sociedade da informação. 2009. 293 f. Dissertação (Mestrado em Direito) - Pontifícia Universidade Católica de São Paulo, São Paulo.

SOCIEDADE MARANHENSE DE DIREITOS HUMANOS (SMDH). Monitoramento de Linchamentos no 
Maranhão (2016). 2017. Disponível em: <http://smdh.org.br/wp-content/uploads/2017/01/LinchamentosMaranha\%CC\%83o-2016.pdf>. Acesso em: 27 mar. 2017.

STRECK, Lenio. Hermenêutica Jurídica e(m) Crise: uma exploração hermenêutica da construção do direito. 10a ed. Porto Alegre: Livraria do Advogado, 2011 , p. 97.

O protótipo do estudante de direito ideal e o "fator olheiras". Revista Consultor Jurídico, 23 de outubro de 2014. Disponível em: <http://www.conjur.com.br/2014-

out-23/senso-incomum-prototipo-estudante-direito-ideal-fator-olheiras>. Acesso em: 05 jan. 2017.

ZUGMAN, Daniel Leib; BASTOS, Frederico Silva. As escolhas por trás do método: contradições, incoerências e patologias do ensino jurídico no Brasil. In.: Ghirardi, José Garcez e Feferbaum, Marina. Ensino do direito em debate: reflexões a partir do $1^{\circ}$ Seminário Ensino Jurídico e Formação Docente /São Paulo: Direito GV, 2013.

Trabalho enviado em 04 de abril de 2017.

Aceito em 04 de julho de 2017. 